\title{
Inheritance of an oviposition behavior by an egg parasitoid
}

\author{
DM Olson and DA Andow \\ Center for Community Genetics and Department of Entomology, University of Minnesota, St. Paul, MN 55108-6125, USA
}

\begin{abstract}
A quantitative genetic study revealed genetic and environmental sources of variance in percentage parasitism of European corn borer egg masses and secondary sex ratios by Trichogramma nubilale. Full and half-sib groups of $T$. nubilale were obtained from a nested mating design, which permitted the partitioning of the variance of $T$. nubilale parasitism of European corn borer egg masses into additive genetic variance, maternal/dominant variance and environmental variance. A mother-daughter regression of the percentage of an egg mass parasitized allowed a determination of the direction of a potential response to selection in the event of maternal effects. No or very little additive genetic effects were associated with the percentage of eggs within a mass
\end{abstract}

parasitized and secondary sex ratios, but a significant amount of the variance for both traits had a maternal and/or dominant genetic source. The relationship between mothers and daughters in egg mass parasitism was positive, and $55.4 \%$ of the progeny of a given mother had behaviors that resemble their mother. Most of the variance had an environmental and/or unknown genetic source implying potentially high phenotypic plasticity associated with all these traits. The presence of maternal effects and phenotypic plasticity could have multiple and complex effects on progeny characters and potential responses to selection.

Heredity (2002) 88, 437-443. DOI: 10.1038/sj/hdy/6800076

Keywords: quantitative genetics; maternal effects; phenotypic plasticity; behavior

\section{Introduction}

Most phytophagous insects are specialists and accounting for the evolution and maintenance of this specialization has been a goal of many behavioral and life history studies of insects (Camara, 1997). For many species, host use by their relatively immobile juveniles depends on female oviposition preferences (eg, Bossart and Scriber, 1999). Thus, genetic variance in oviposition preference may be an initial requirement for the evolution of host specialization. A few studies of oviposition preference variation within phytophagous insect populations show variation in the genetic basis for this trait (reviewed in Jaenike and Holt, 1991; Tucié et al, 1997; Bossart and Scriber, 1999), and hybridization studies of different populations show wide variation in the number of loci affecting this trait, the relative contributions of dominance, additivity, and epistasis, and the roles of sexlinked versus autosomal genes (reviewed in Messina and Slade, 1997; Janz, 1998). The variable findings make generalizations difficult, although heritable variance, in the broad and narrow sense, has been uncovered in most of the species studied. Maintenance of this genetic variability may arise through positive genetic correlations between preference and larval performance, but the evidence for this is weak (Jaenike and Holt, 1991). Alternatively, genetic variance in oviposition preference could be

Correspondence: DM Olson, Crop Protection \& Management Research Laboratory, USDA-ARS Tifton, GA, 31793, USA.

E-mail:dolson@tifton.es.peachnet.edu

Received 26 September 2001; accepted 14 February 2002 maintained through frequency and/or density dependent processes in the populations (Jaenike and Holt, 1991). More studies, such as those of Sokolowski et al (1997) that simultaneously look at the genetic basis and the potential effects of ecological interactions on insect behavior may be needed to more fully understand the evolution of behavior and the maintenance of the variability in host-use observed.

Research on parasitoids (insects that develop on or within other insect species) of agricultural pests has generated a tremendous amount of information on the behavior and ecology of many different species. A recurring problem within this work is how the various behaviors, and more recently, sex ratio and mating systems (Antolin, 1999) affect Darwinian fitness (Godfray, 1994) and the dynamics of populations (eg, Murdoch, 1994). Because of the unusually direct link between oviposition behavior and fitness gains, parasitoids provide a unique opportunity for studies of the evolution of behaviors, such as host finding behavior, the role of environmental factors on the evolution of those behaviors (West-Eberhard, 1989; Scheiner, 1993; Godfray, 1994), and ultimately, the dynamics of populations (Murdoch, 1994).

An adaptive response to natural selection depends on the existence of additive genetic variance in the traits involved (Falconer, 1981). Many studies have been conducted that provide evidence for genetic variation in life history and behavioral traits of parasitoids that use techniques allowing estimation of broad-sense heritability (reviewed in Carton et al, 1989; Cronin and Strong, 1996; Raquel et al, 1998), but these studies have not distinguished additive genetic variance from other forms of 
genetic variance. The more detailed techniques of diallel or pedigreed crosses (eg, Antolin, 1992, 1999; Henter, 1995), can partition this heritable variation into its components, and identify potential maternal influences on a trait. Such maternal effects can have significant evolutionary consequences (papers in Mousseau and Fox, 1998). The studies of Henter (1995) and Schmidt (1991) have focused on some of the fundamental fitness characters for a parasitoid, its ability to find, handle and parasitize its host, and Antolin (1992, 1999) focused on sex ratio and how sex ratio and mating systems might evolve together to purge inbreeding depression.

Trichogramma species are minute parasitoids of eggs of other insects, primarily Lepidoptera. Trichogramma species have been used and studied as biological control agents of many lepidopterous pests (Stinner, 1977). The typical practice is to rear large numbers in a laboratory colony and release them to flood the pest population with parasitoids. Despite numerous attempts dating back to around 1900, relatively few releases of Trichogramma have proven to be effective in the field (Stinner, 1977). High variability in their effectiveness does not seem related to any particular environmental factor, and it is possible that the laboratory-rearing environment may induce variability in the host-finding or host-handling ability of the wasps, thereby moderating the effectiveness of the releases in the field (Andow et al, 1995). Consequently for T. nubilale and Trichogramma species in general, the laboratory-rearing environment is a significant environment in which to understand evolution, and not merely an experimentally convenient one. We conducted a quantitative genetic study to estimate the additive genetic and maternal/ dominance sources of variance associated with a host-handling behavior, the percent of an egg mass parasitized by an individual female. We also conducted a similar study on secondary sex ratios produced to investigate the potential evolution of sex ratio in this haplodiploid population.

\section{Materials and methods}

\section{Colony composition}

A relatively large population (5000-10000) of T. nubilale Ertle and Davis (Hymenoptera: Trichogrammatidae) has been reared in the laboratory on the host species Ostrinia nubilalis (Hübner) (Lepidoptera: Crambidae) at $25^{\circ} \mathrm{C}, 65$ $\pm 5 \% \mathrm{RH}, 16: 8$ (L:D). Wasps were originally recovered from eggs of $O$. nubilalis in Delaware and at the time of the experiments had been maintained in culture for c. 200 generations. The host species was also reared in the lab and established using Pasteur's method for eliminating microsporidian disease, monitored and determined to be disease-free at the time of these experiments.

Ostrinia nubilalis females lay their eggs in masses of 10 to 40+ eggs in the laboratory; a maximum of two T. nubilale wasps can develop within each host, and the wasps can discriminate host eggs previously parasitized (Olson, 1997), similar to other species of Trichogramma (eg, Salt, 1935; Strand, 1986). Individual females from our laboratory population show variable but low percentage parasitism of host egg masses when foraging alone and egg mass size is controlled, and this variable, low percentage has persisted for at least 50 generations (Olson, 1997). This variability is also not related to the size of females which can differ depending on the number eclosing per host egg (Olson, 1997). Field populations of T. nubilale naturally parasitize a high percentage of an $O$. nubilalis egg mass (DA Andow, unpublished data).

To document the behavior of females in the colony at the time of our experiments, we measured the number of eggs parasitized, percent of the egg mass parasitized, the time a female was associated with the egg mass and secondary sex ratios produced by females. We found no differences in primary and secondary sex ratios for this population $(0.23 \pm 0.08$ ( $\%$ males) and $0.23 \pm 0.09$ for primary and secondary sex ratio, respectively; $n=25$ females parasitizing an egg mass with 10 eggs). Individual females were allowed to parasitize an egg mass at the center of a $1.5 \mathrm{~cm}$ diameter wax paper disk. The time that females were associated with the egg mass was measured to the nearest minute from the initial contact until they left the egg mass and touched the edge of the wax paper. Egg mass association was measured in this way because in the laboratory colony, a female leaving an egg mass at this distance would normally encounter a different egg mass. The number of eggs parasitized was determined by counting the number of blackened, parasitized host eggs. Host eggs blacken when the parasitoid begins to pupate. Direct observations of oviposition indicated that $87 \%$ of eggs parasitized would later blacken (Olson, 1997). The ratio of the number of blackened eggs to the total number of eggs in the egg mass was the estimate of the percent of the egg mass parasitized. The total number of male and female progeny from parasitized egg masses was counted after killing individuals by freezing.

\section{Inheritance}

Resemblance among relatives: Several experimental designs allow the partitioning of the genetic and environmental components of variance associated with a trait(s) among individuals of known relatedness (Falconer, 1981). We used a full-sib/half-sib nested design in the analysis of the percentage of an egg mass parasitized (Figure 1a) because fewer crosses per parent were necessary than with other designs.

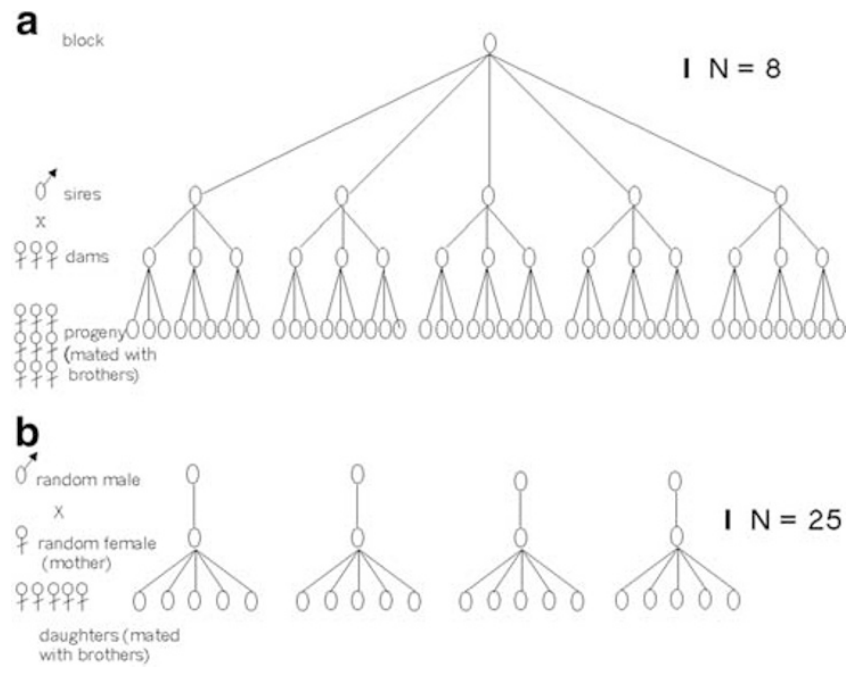

Figure 1 Diagram of the nested mating design (a) and the motherdaughter regression (b). a: represents one block (eight total), b: represents four of the 25 families. 
The analysis of the nested design (Falconer, 1981; Becker, 1986) was adjusted for the haplo-diploid genetics or sex-linked inheritance of Trichogramma species to partition the variance into additive, maternal/dominant, and environmental sources (Table 1). The between-sire variance component estimates the covariance of half-sibs, and in a haplo-diploid organism, this is equal to $\frac{1}{2} \mathrm{~V}_{\mathrm{A}}$, the additive genetic variance. The between dam variance component is the covariance of full-sibs less the covariance of half-sibs, and with haplodiploidy this estimates the additive, maternal and dominant effects of the traits as $\frac{1}{4} \mathrm{~V}_{\mathrm{A}}+\mathrm{V}_{\mathrm{M}}+\frac{1}{2} \mathrm{~V}_{\mathrm{D}}$.

Estimation of half-sib and full-sib covariance was accomplished using a hierarchical mating design (Figure 1a), where males (sires) are each mated to several females (dams). For each replicate block, 20 O. nubilalis egg masses each containing about $20 \mathrm{~T}$. nubilale pupae were randomly chosen from a colony of $T$. nubilale and placed individually in small petri dishes until wasp eclosion. Males emerge before females, and from each of five petri dishes a male to be used as a sire was randomly chosen and placed in a gelatin capsule with a drop of honey. The remaining progeny in these dishes were discarded. All males in the remaining 15 petri dishes were removed prior to female emergence and a female to serve as a dam was randomly chosen from each dish and placed within a gelatin capsule containing a male. This process was repeated until each male had mated with three females. A single male has the capacity to successfully inseminate at least nine females (three virgin males each mated to nine virgin females that produced mean (SD) secondary sex ratios (\% females) of $83.8 \pm 4.6 \%, n=26$ ), with no change related to mating order, so we did not control for order of mating. Each mated dam was placed in a petri dish with a one-day-old unparasitized $O$. nubilalis egg mass containing about 25 eggs. Mated dams were allowed to parasitize the egg mass for $24 \mathrm{~h}$. The egg masses were incubated until wasp eclosion. For each dam, three 1-day-old, honey-fed female progeny that had mated with their brothers were randomly chosen for observation. A total of five sires (half-sib families), 15 dams (full-sib families) and 45 progeny represented one replicate block, and eight replicate blocks were obtained over a 3-month period. Females that were not mated (indicated by the production of all males by this arrhenotokous species), did not encounter the egg mass after $2 \mathrm{~h}$, or did not produce parasitized eggs after egg mass

Table 1 The observational components of variance in a sib analysis and parent-offspring regression for a haplo-diploid organism

Observational
component causal components estimated

\section{Sib analysis}

Sires

Dams

Progenies

Total

$$
\begin{array}{cc}
\sigma^{2} \mathrm{~S}=\mathrm{COV}_{(\mathrm{HS})} & \frac{1}{2} \mathrm{~V}_{\mathrm{A}} \\
\sigma^{2} \mathrm{D}=\mathrm{COV}^{(\mathrm{FS})}-\mathrm{COV}_{(\mathrm{HS})} & \frac{1}{4} \mathrm{~V}_{\mathrm{A}}+\frac{1}{2} \mathrm{~V}_{\mathrm{D}}+\mathrm{V}_{\mathrm{M}} \\
\sigma^{2} \mathrm{~W}=\mathrm{V}_{\mathrm{P}}-\mathrm{COV}_{(\mathrm{FS})} & \frac{1}{4} \mathrm{~V}_{\mathrm{A}}+\frac{1}{2} \mathrm{~V}_{\mathrm{D}}+\mathrm{V}_{\mathrm{E}} \\
\sigma_{\mathrm{T}}^{2}=\sigma^{2}{ }_{\mathrm{S}}+\sigma^{2}{ }_{\mathrm{D}}+\sigma^{2}{ }_{\mathrm{W}}=\mathrm{V}_{\mathrm{P}} & \mathrm{V}_{\mathrm{A}}+\mathrm{V}_{\mathrm{D}}+\mathrm{V}_{\mathrm{M}}+\mathrm{V}_{\mathrm{E}}
\end{array}
$$

Parent-offspring

regression

Mother-daughter $\quad \mathrm{COV}_{(\mathrm{md})} / \sigma^{2} \mathrm{~m} \quad \frac{1}{2} \mathrm{~V}_{\mathrm{A}}+\mathrm{V}_{\mathrm{M}}$

(md) encounter, were discarded bringing the total number of sires, dams and progeny to 39,103 , and 300, respectively.

The effect of replicate block, full-sib family and halfsib family on the number of eggs parasitized, percent of the egg mass parasitized, the time associated with the egg mass and secondary sex ratio were analyzed with ANOVA using SAS procedure GLM and type III sums of squares (PC SAS version 6.11, SAS Institute, 1995). We used untransformed data for the number and percentage of eggs parasitized and the time on the egg mass (Levene's test: $P>0.05$ ). The untransformed data for secondary sex ratio are reported as no transformation stabilized the variance. The variance components were constrained to $\geq 0$ (Shaw and Geyer, 1997); effects with negative variance were removed and the significant effects from the adjusted model are reported here. The effects with negative variance are indicated by zero observational variance. Tests were constructed from the expected mean squares provided by the random option of GLM.

The correlation between the percentage of eggs parasitized within an egg mass and the time that the female was associated with the egg mass, and the correlation between the percentage of eggs parasitized and secondary sex ratio was investigated by estimating phenotypic and genetic correlations between the traits. We used the data from the full-sib and half-sib mating design and linear regression for estimates of phenotypic correlations (SAS version 6.11, SAS Institute, 1995) and methods described in Becker (1986) for genotypic correlations.

There was slight variability in egg mass size, and variability in egg mass parasitism may be associated with differences in frequencies of grooming or resting among females while on the egg mass thereby creating additional environmental variability. To investigate the potential significance of this potential nuisance parameter, we estimated the dependence of the percentage of eggs parasitized and time associated with the egg mass on the number of eggs in the mass using a linear regression model (SAS version 6.11, SAS Institute, 1995).

Parent-offspring regression: We also conducted a study to analyze the resemblance between mothers and their offspring (Figure 1b). The regression coefficient from the regression of the mean of daughters on the value of their mothers estimates the covariance of mothers and daughters over the variance in mothers (Falconer, 1981, Table 1 ), which equals $\frac{1}{2} V_{A}+V_{M}$ (Table 1$)$. For each of 25 mothers, the number of eggs parasitized, the percent of an eggs mass parasitized, and the time the mother was associated with the egg mass was determined as above. After offspring eclosion, five honey-fed and sib-mated female offspring of each mother were randomly chosen, placed individually in another petri dish with an egg mass containing about 20 eggs and evaluated as above. A total of 104 daughters were obtained for the analysis. The relationship between mothers and daughters in the percentage of the egg mass parasitized was tested using a linear regression analysis (SAS version 6.11, SAS Institute, 1995) with the values of mothers as the dependent variable and the mean value of daughters as the response. Estimates of genotypic correlations between the percentage of eggs parasitized within an egg mass and the time that the female was associated with the egg mass 


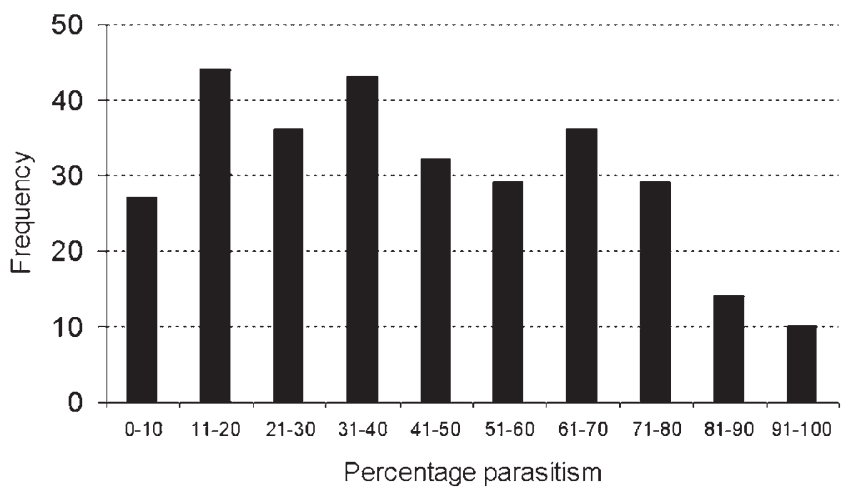

Figure 2 Distribution of the percentage of an egg mass parasitized. $n=300$ females.

were obtained using the methods described in Becker (1986).

\section{Results}

\section{Colony composition}

Most females parasitized less than $50 \%$ of the egg mass (Figure 2, 61\% of the 300 females observed). The average percent of the egg mass parasitized, and the number of eggs parasitized per egg mass was $42 \%$ and 10.2 eggs, respectively. The average number of eggs within the mass was $24.4 \pm 4.0 \mathrm{SD}$, indicating that on average females left most of the egg mass unparasitized. This contrasts dramatically with this colony's behavior when they were initially collected from the field, when most females parasitized $\geq 80 \%$ of an egg mass $(n=8,4$ th generation field collected females given an egg mass with 25 eggs; mean (SD) percent parasitism $=79 \% \pm 14 \%$ ), which indicates that evolution has occurred in the colony.

\section{Inheritance}

The ANOVA of the full sib/half sib nested mating experiment is shown in Table 2. The variance associated with the replicate block did not significantly influence the time associated with an egg mass, the number of eggs parasitized and the percentage of an egg mass parasitized (Table

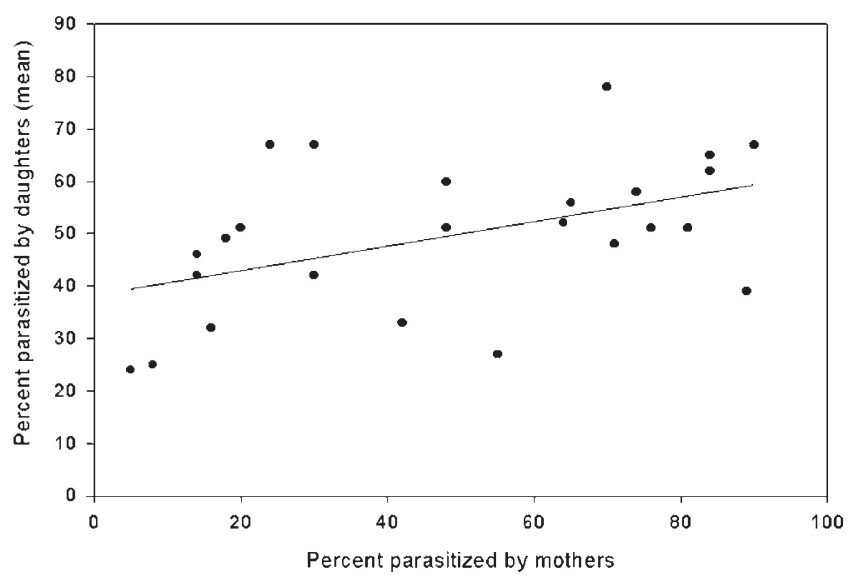

Figure 3 Mother-daughter regression of the percentage of an egg mass parasitized. $n=25$ mothers and 104 daughters. $\mathrm{Y}=0.236 \mathrm{x}^{*}+$ $138.226^{* *}, r^{2}=0.224,{ }^{*} P<0.001,{ }^{* *} P<0.017$.
2), implying that female behavior was not significantly influenced by potential differences between host egg masses and the day of observations. The variance in the number of eggs parasitized and the percentage of an egg mass parasitized were significant for dams, but not for sires (Table 2). Thus, there was none or relatively little direct additive genetic variance for these traits, but between $12 \%$ and $14 \%$ of the variance had a maternal and/or dominant genetic source (Table 2). The variance in secondary sex ratio was significant for sires (Table 2), indicating a small amount of direct additive genetic variance associated with this trait. The progeny component of the variance accounted for between $86 \%$ and $91 \%$ of the variance of egg mass parasitism (Table 2). Therefore, most of the variance in egg mass parasitism and sex ratio had unknown environmental and/or genetic sources attributable to individual females.

The percentage of the egg mass parasitized was influenced by the time associated with the egg mass ( $\mathrm{y}=$ $\left.0.5325 x+17.144, r^{2}=0.489, P<0.001, n=300\right)$. There was also a significant positive genetic correlation between the percentage of the egg mass parasitized and the time on the egg mass arising from dam effects, although the resulting correlation was unfeasible $(r \pm \mathrm{se}=1.11 \pm 0.49$, $t=2.27, \mathrm{df}=64, P=0.027)$, and from environmental sources $(r \pm$ se $=0.729 \pm 0.03, t=26.33, \mathrm{df}=197, P=$ 0.000 ). The secondary sex ratio of $T$. nubilale was significantly and positively correlated with the percentage parasitism of an egg mass $\left(\mathrm{y}=0.488 \mathrm{x}+0.100, r^{2}=0.076, P\right.$ $<0.001, n=300$ ). There was also a significant positive genetic correlation between the percentage of the egg mass parasitized and secondary sex ratio arising from dam effects $(r \pm \mathrm{se}=0.638 \pm 0.196, t=3.26, \mathrm{df}=64, P=$ $0.002)$ and from environmental sources $(r \pm$ se $=0.211 \pm$ $0.005, t=42.20, \mathrm{df}=197, P=0.000$ ). These results imply that correlated responses for increased or decreased percentage of an egg mass parasitized, the time spent on an egg mass and sex ratio are possible depending on the genetic basis of the dam effect.

Parent-offspring regression: The mother-daughter regression analysis demonstrated a significant positive relationship between mothers and daughters in the percentage of an egg mass parasitized (Figure 2). The regression coefficient estimated the broad sense heritability as 0.48 , but because the previous result implies that there was no additive variance this variance associated with the broad sense heritability must have arisen from maternal effects (Table 1). The covariance of mothers and daughters of 30.3 estimated from the regression coefficient and the variance from mothers, corresponds to $55.4 \pm 24.1 \% \mathrm{SD}(n=13)$ of the offspring produced by females that parasitized a high percentage of the egg mass also parasitized a high percentage of the egg mass, and $55.4 \pm 39.9 \%(n=12)$ of the offspring of females that parasitized a low percentage of the egg mass also parasitized a low percentage of the egg mass. Similar to the full/half sib analysis, there was a significant positive genetic correlation between the percentage of an egg mass parasitized and the time females spend on the egg mass $(r \pm \mathrm{se}=0.670 \pm 0.315, t=2.16, \mathrm{df}=24, P=0.041)$. 
Table 2 Nested analysis of variance on the time associated with an egg mass (min), percent parasitism, the number of eggs parasitized and secondary sex ratio for female Trichogramma nubilale on European corn borer egg masses. Type III sums of squares were used, and expected mean squares were obtained using the random option of SAS GLM (SAS, 1985)

\begin{tabular}{|c|c|c|c|c|c|}
\hline \multirow[t]{2}{*}{ Source of variation } & \multirow[t]{2}{*}{$D f$} & \multirow[t]{2}{*}{ MS } & \multirow[t]{2}{*}{$F$} & \multicolumn{2}{|c|}{ Variance components } \\
\hline & & & & Observed & Causal (\%) \\
\hline \multicolumn{6}{|l|}{ Time on egg mass (min) } \\
\hline Block & 7 & 1436.58 & 1.35 & 10.37 & 1 \\
\hline Sire (nested within block) & 31 & 1060.63 & 0.99 & -0 & $\frac{1}{2} \mathrm{~V}_{\mathrm{A}}=0$ \\
\hline Dam (nested within sire) & 64 & 1063.22 & 1.26 & 75.79 & $\frac{1}{4} \mathrm{~V}_{\mathrm{A}}+\mathrm{V}_{\mathrm{M}}^{\mathrm{A}}+\frac{1}{2} \mathrm{~V}_{\mathrm{D}}=8$ \\
\hline Progeny (error) & 197 & 843.14 & - & 843.14 & $\frac{1}{4} \mathrm{~V}_{\mathrm{A}}+\frac{1}{2} \mathrm{~V}_{\mathrm{D}}+\mathrm{V}_{\mathrm{E}}=91$ \\
\hline \multicolumn{6}{|l|}{ Percent parasitism } \\
\hline Block & 7 & 949.16 & 1.36 & 4.85 & 2 \\
\hline Sire (nested within block) & 31 & 696.01 & 0.89 & -0 & $\frac{1}{2} \mathrm{~V}_{\mathrm{A}}=0$ \\
\hline Dam (nested within sire) & 64 & 776.82 & $1.53^{*}$ & 92.39 & $\frac{1}{4} \mathrm{~V}_{\mathrm{A}}+\mathrm{V}_{\mathrm{M}}+\frac{1}{2} \mathrm{~V}_{\mathrm{D}}=14$ \\
\hline Progeny (error) & 197 & 508.54 & - & 508.54 & $\frac{1}{4} V_{A}+\frac{1}{2} V_{D}+V_{E}=84$ \\
\hline \multicolumn{6}{|l|}{ Number of eggs parasitized } \\
\hline Block & 7 & 31.31 & 0.77 & -0 & 0 \\
\hline Sire (nested within block & 31 & 40.47 & 0.86 & -0 & $\frac{1}{2} V_{A}=0$ \\
\hline Dam (nested within sire) & 64 & 46.65 & $1.48^{* *}$ & 5.18 & $\frac{1}{4} \mathrm{~V}_{\mathrm{A}}+\mathrm{V}_{\mathrm{M}}+\frac{1}{2} \mathrm{~V}_{\mathrm{D}}=12$ \\
\hline Progeny (error) & 197 & 31.61 & - & 31.61 & $\frac{1}{4} \mathrm{~V}_{\mathrm{A}}+\frac{1}{2} \mathrm{~V}_{\mathrm{D}}+\mathrm{V}_{\mathrm{E}}=88$ \\
\hline \multicolumn{6}{|l|}{ Secondary sex ratio } \\
\hline Block & 7 & 49.08 & 0.23 & -0 & 0 \\
\hline Sire (nested within block) & 31 & 288.84 & $1.27^{*}$ & 6.27 & $\frac{1}{2} \mathrm{~V}_{\mathrm{A}}=3$ \\
\hline Dam (nested within sire) & 64 & 227.57 & 1.48 & 20.31 & $\frac{1}{4} \mathrm{~V}_{\mathrm{A}}+\mathrm{V}_{\mathrm{M}}+\frac{1}{2} \mathrm{~V}_{\mathrm{D}}=11$ \\
\hline Progeny (error) & 197 & 168.57 & - & 168.57 & $\frac{1}{4} \mathrm{~V}_{\mathrm{A}}+\frac{1}{2} \mathrm{~V}_{\mathrm{D}}+\mathrm{V}_{\mathrm{E}}=86$ \\
\hline
\end{tabular}

$\mathrm{V}_{\mathrm{A}}$ = additive genetic variance, $\mathrm{V}_{\mathrm{MD}}=$ maternal/dominance variance, $\mathrm{V}_{\mathrm{E}}=$ environmental variance. Negative estimates were assumed not to contribute to the phenotypic variance and are shown as $-0 .{ }^{*} P<0.016,{ }^{* *} P<0.024$.

\section{Discussion}

The colony consists of a high proportion of females that parasitize a low percent of an egg mass, and there is no $\mathrm{V}_{\mathrm{A}}$ associated with this trait in this population. Although we can make no inferences from the present study about wild populations, we do know that egg masses found in nature are parasitized uniformly at a high level by $T$. nubilale. This implies that some evolution has occurred associated with the colony. Additive variance could have been reduced in this population through genetic bottlenecks or through selection on sex ratio and/or, the percentage of eggs parasitized within an egg mass, which was phenotypically and genotypically correlated with sex ratio. The number of founder females came from between 50 and 100 different field collected parasitized egg masses (average size 20 eggs), which makes it unlikely that an initial genetic bottleneck could have occurred. However, variability in host availability through time and the resulting fluctuations in conspecific densities could have caused several genetic bottlenecks since the inception of the colony. The result could be that $\mathrm{V}_{\mathrm{A}}$ has been reduced through random genetic drift, extensive inbreeding or strong selection within this population.

Several other laboratory-reared Trichogramma species have been studied for the relative importance of genetic and environmental sources of variance associated with oviposition behavior (reviews in Hopper et al, 1993 and Schmidt, 1991). All of these researchers estimated broad sense heritabilities by full-sib resemblance. The authors implied that selection on the traits may be possible because of heritable variation, and one study found a weak response to selection over five generations (Schmidt, 1991). The magnitude of the linear correlation between maternal and daughter response found in the traits studied are similar to those observed here in the percent of eggs in an egg mass parasitized by T. nubilale. For T. nubilale, about $55 \%$ of the progeny of a single mother have levels of the percent of an egg mass parasitized that are similar to their mother, and the variance found was similar in magnitude to that found in the nested sib-design. Similar to what we found here for the percent of an egg mass parasitized, which did not have significant additive variance, the variance that has been found in other oviposition behaviors might not have a high additive component.

The majority of the variance associated with the percent of an egg mass parasitized has an environmental and/or unknown genetic source. Some females parasitize all of an egg mass while others parasitize only one or two eggs before leaving. In this parasitoid population, phenotypic plasticity in egg mass parasitism may be considerable. The adaptive significance of this variability remains to be investigated.

The mechanism(s) for differential percentages of an egg mass parasitized are unclear, but may be related to differences in individual responses to factors that influence patch residence times. For example, Wajnberg et al (1999) found differences among families of an egg parasitoid in the effect of oviposition on patch-residence time, possibly from differential responses to chemical 'marks' females leave on hosts they have parasitized. Reduction in patch time from oviposition is thought to be an adaptive patch-leaving mechanism when host patches are small or when hosts are uniformly distributed (Iwasa et al, 1981). By this reasoning, selection in the laboratory should lead to a uniformly low percent egg mass parasit- 
ism by T. nubilale. The colony is polymorphic for this trait with individuals parasitizing high or low percentages of an egg mass (Figure 2). Within the laboratory colony, several factors may create an environment with widely fluctuating conspecific densities (Olson, 1997) leading to complex selection regimes. In any event, because percent parasitism was strongly correlated phenotypically and genotypically with egg mass association time, our results suggest that females were behaving as if they were using a fixed giving up time that varied among individuals rather than a dynamic one.

A significant amount of the variance in the percentage of an egg mass parasitized was attributable to maternal effects. Maternal effects arise from variation attributable to several causes including: (1) effects of maternal, environmentally influenced condition on developing progeny, which includes transfer of disease from mother to offspring; (2) variation in organelle genomes; and (3) nuclear genetic variation at loci expressed in maternal individuals and influencing offspring traits. Although there are still statistical and logistic problems associated with detection and measurement of maternal effects, several techniques have been utilized with some success depending on the organism (papers in Mousseau and Fox, 1998). The use of a three-generation nested design (Byers et al, 1997) or a diallel crossing scheme (Antolin, 1992, 1999) may be most useful for animal studies and allow further partitioning of the maternal variance into genetic and environmental sources.

The weak additive and strong maternal component of the trait(s) associated with egg mass parasitism implies that alteration of this trait(s) can be achieved through the evolution of the maternal component to the extent that the $V_{M}$ has a heritable genetic component. Alteration of traits can also be achieved through evolution of the reaction norm after selection of variants associated with environmental conditions and plasticity (Scheiner, 1993), and/or when particular phenotypes are repeatedly associated with and consistently respond to a particular fitness-affecting condition (West-Eberhard, 1989). However, as has been illustrated and discussed by many researchers (papers in Scheiner, 1993; West-Eberhard, 1989 Mousseau and Fox, 1998;), the presence of maternal effects and phenotypic plasticity could have multiple and complex effects on progeny characters and potential responses to selection.

\section{Acknowledgements}

We thank R Shaw, H Henter, P Timper and G Rains for their very helpful comments on various versions of this manuscript. Funding for this project has been approved by the Minnesota Legislature Subd. 6(a) as recommended by the Legislative Commission on Minnesota Resources from the Minnesota Environment and Natural Resources Trust Fund, a biological control grant from the University of Minnesota, Department of Agriculture, and The Center for Community Genetics, Department of Ecology and Evolution, University of Minnesota.

\section{References}

Andow DA, Klacan GC, Bach D, Leahy TC (1995). Limitations of Trichogramma nubilale (Hymenoptera: Trichogrammatidae) as an inundative biological control of Ostrinia nubilalis (Lepidoptera: Crambidae). Environ Entomol 24: 1352-1357.
Antolin MF (1992). Sex ratio variation in a parasitic wasp I. diallel cross. Evolution 46: 1511-1524.

Antolin MF (1999). A genetic perspective on mating systems and sex ratios of parasitoid wasps. Res Popul Ecol 41: 29-37.

Becker TCM (1986). A Manual of Quantitative Genetics. Academic Enterprises: Pullman, Washington.

Bosart JI, Scriber JM (1999). Preference variation in the polyphagous tiger swallowtail butterfly (Lepidoptera: Papilionidae). Environ Entomol 28: 628-637.

Byers DL, Platenkamp GAJ, Shaw RG (1997). Variation in seed characters in Nemophila menziesii: evidence of a genetic basis for maternal effect. Evolution 51: 1445-1456.

Camara MD (1997). A recent host range expansion in Junonia coenia Hübner (Nymphalidae): oviposition preference, survival, growth, and chemical defense. Evolution 51: 873-884.

Carton Y, Capy P, Nappi AJ (1989). Genetic variability of hostparasite releationship traits: utilization of isofemale lines in a Drosophila simulans parasitic wasp. Genet Sel Evol 21: 437-446.

Cronin JT, Strong DR (1996). Genetics of oviposition success of a thelytokous fairyfly parasitoid, Angrus delicatus. Heredity 76: 43-54.

Falconer DS (1981). Introduction to Quantitative Genetics. 3rd edn, John Wiley \& Sons: New York.

Godfray HCL (1994). Parasitoids: Behavioral and Evolutionary Ecology. Princeton University Press: New Jersey.

Henter HJ (1995). The potential for coevolution in a host-parasitoid system. II. Genetic variation within a population of wasps in the ability to parasitize an aphid host. Evolution 49: 439-445.

Hopper KR, Rousch RT, Powell W (1993). Management of genetics of biological control introductions. Annu Rev Entomol 38: $38-51$.

Iwasa Y, Higashi M, Yamamura N (1981). Prey distribution as a factor determining the choice of optimal foraging strategy. Am Nat 117: 710-723.

Jaenike J, Holt RD (1991). Genetic variation for habitat preference: evidence and explanations. Am Nat 137: 67-90.

Janz N (1998). Sex-linked inheritance of host-plant specialization in a polyphagous butterfly. Proc R Soc Lond B 265: 1675-1678.

Messina FJ, Slade AF (1997). Inheritance of host-plant choice in the seed beetle Callosobruchus maculatus (Coleoptera: Bruchidae). Ann Entomol Soc Am 90: 848-855.

Mousseau TA, Fox CW (1998). Maternal Effects as Adaptations, Oxford University Press: New York.

Murdoch WW (1994). Population regulation in theory and practice. Ecology 75: 271-287.

Olson DM (1997). Fitness and Inheritance of Oviposition Behaviors of a Parasitoid in Populations with High Conspecific Densities. PhD dissertation, University of Minnesota, USA.

Raquel P, Kaiser L, Wajnberg E, Carton Y, Pham-Delègue M (1998). Genetic variability of conditioned probing responses to a fruit odor in Leptopilina boulardi (Hymenoptera: Eucoildae), a Drosophila parasitoid. Behav Genet 28: 67-73.

Salt G (1935). Experimental studies in insect parasitism. III. Host selection. Proc R Soc Lond B Biol Sci 117: 413-435.

SAS Institute (1995). SAS user's guide: statistics. SAS Institute: Cary, NC.

Scheiner SM (1993). Genetics and evolution of phenotypic plasticity. Annu Rev Ecol Syst 23: 35-68.

Schmidt JM (1991). The inheritance of clutch size regulation in Trichogramma species (Hymenoptera: Chalcidoidea: Trichogrammatidae). In: Proceedings of the 5th workshop of the global IOBC working group "quality control of mass reared organisms", Wageningen: The Netherlands. pp 26-37.

Shaw FH, Geyer CJ (1997). Estimation and testing in constrained covariance component models. Biometrika 84: 95-102.

Sokolowski MB, Pereira HS, Hughes K (1997). Evolution of foraging behavior in Drosophila by density-dependent selection. Proc Nat Acad Sci USA 94: 7373-7377.

Stinner RE (1977). Efficacy of inundative releases. Annu Rev Entomol 22: 515-531. 
Strand MR (1986). The physiological interactions of parasitoids with their hosts and their influence on reproductive strategies. In: Waage JK, Greathead D (eds) Insect Parasitoids, Academic Press: London. pp 97-136.

Tucié N, Mikuljanac S, Stojkovié O. (1997). Genetic variation and covariation among life history traits in populations of Acan- thoscelides obtectus maintained on different hosts. Entomol Exp et Appl 85: 247-256.

Wajnberg E, Rosi MC, Colazza S (1999). Genetic variation in patch time allocation in a parasitic wasp. Anim Ecol 68: 121-133.

West-Eberhard MJ (1989). Phenotypic plasticity and the origins of diversity. Annu Rev Syst 20: 249-278. 